Supporting Information

\title{
Seawater-assisted self-healing of catechol polymers via hydrogen bonding and coordination interactions
}

Jincai Li, Hirotaka Ejima, and Naoko Yoshie*

Institute of Industrial Science, The University of Tokyo, 4-6-1 Komaba, Meguro-ku, Tokyo 153-8505, Japan

*Corresponding author

E-mail: yoshie@iiis.u-tokyo.ac.jp 
Synthesis of acrylic anhydride<smiles>C=CC(=O)O</smiles>

Acrylic acid

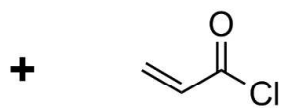

Acryloyl chloride

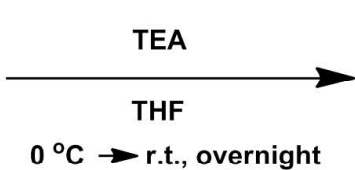

$\rightarrow$ r.t., overnight

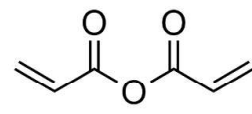

Acrylic anhydride

Scheme S1. Synthetic scheme of acrylic anhydride.

Acrylic anhydride was synthesized by using a previously reported procedure with modifications. ${ }^{1,2}$ To a nitrogen-purged $1 \mathrm{~L}$ two-neck flask, $750 \mathrm{~mL}$ of tetrahydrofuran (THF) and $40.0 \mathrm{~mL}$ of acrylic acid $(42.3 \mathrm{~g}, 587 \mathrm{mmol})$ were added. The solution was stirred and $86.0 \mathrm{~mL}$ of triethylamine (TEA, $62.3 \mathrm{~g}, 616 \mathrm{mmol}$ ) was added. Then 50.0 $\mathrm{mL}$ of acryloyl chloride (55.8 $\mathrm{g}, 616 \mathrm{mmol})$ was dropped slowly into the solution in an ice bath by using a dropping funnel. After $2 \mathrm{~h}$, the solution was left with constant stirring at room temperature overnight. The precipitate was removed by filtration, and then the solvent was removed by rotary evaporation. The residue was dissolved in 150 $\mathrm{mL}$ of $\mathrm{CH}_{2} \mathrm{Cl}_{2}$, and the resulting solution was washed twice with $100 \mathrm{~mL}$ of $2 \%$ $\mathrm{NaHCO}_{3}$ and once with $100 \mathrm{~mL}$ of brine and then dried over $\mathrm{Na}_{2} \mathrm{SO}_{4}$. After filtration, the solvent was removed by rotary evaporation to yield a red oil. This oil was distilled at $90{ }^{\circ} \mathrm{C}$ under reduced pressure to afford acrylic anhydride as a colorless liquid (48.5 g, yield 66\%). ${ }^{1} \mathrm{H}$ NMR (400 MHz, methanol- $\left.d_{4}, \delta\right): 6.13$ (dd, $2 \mathrm{H}, \mathrm{HCH}=$ trans to $\left.\mathrm{CO}_{2}, J=1.2,10.4 \mathrm{~Hz}\right), 6.25(\mathrm{dd}, 2 \mathrm{H}, \mathrm{CH}=, J=10.4,17.2 \mathrm{~Hz}), 6.53$ (dd, 2H, $\mathrm{HC} H=$ cis to $\mathrm{CO}_{2}, J=1.2,17.2 \mathrm{~Hz}$ ). 


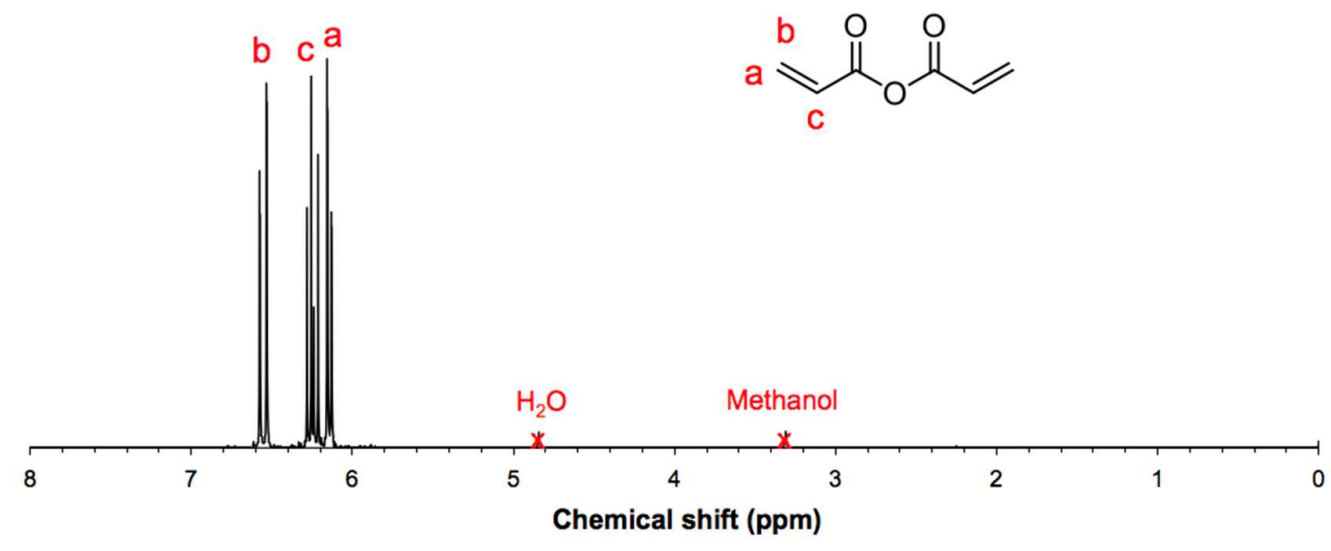

Figure S1. ${ }^{1} \mathrm{H}$ NMR spectrum of acrylic anhydride (400 MHz, methanol- $\left.d_{4}\right)$.

\section{Synthesis of dopamine acrylamide (DA)}<smiles>Oc1ccc(CCNCCl)cc1O</smiles>

Dopamine hydrochloride

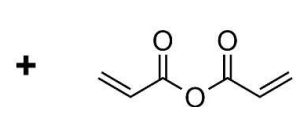

Acrylic anhydride

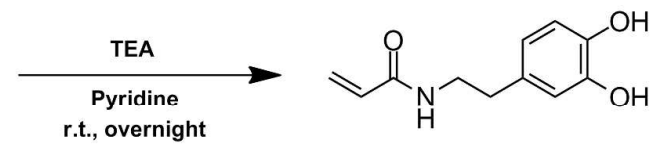

Dopamine acrylamide

Scheme S2. Synthetic scheme of DA.

DA was synthesized by using a previously reported procedure with modifications. ${ }^{3}$ To a nitrogen-purged $300 \mathrm{~mL}$ two-neck flask, $20.0 \mathrm{~g}$ of dopamine hydrochloride (105 mmol) and $160 \mathrm{~mL}$ of anhydrous pyridine were added. The solution was stirred and $29.2 \mathrm{~mL}$ of TEA $(21.3 \mathrm{~g}, 211 \mathrm{mmol})$ was added. Then, $13.3 \mathrm{~g}$ of acrylic anhydride (105 mmol) in $10 \mathrm{~mL}$ of anhydrous THF was dropped slowly into the solution by using a dropping funnel. The reaction was stirred under a nitrogen atmosphere at room temperature overnight. The solvent was removed by rotary evaporation, and the residue was extracted with $150 \mathrm{~mL}$ of acetone. After filtration, the solvent was removed by rotary evaporation, and then $150 \mathrm{~mL}$ of deionized water and $200 \mathrm{~mL}$ of ethyl acetate were added. The solution was stirred for $1 \mathrm{~h}$, and the aqueous layer was removed by using a separating funnel. The organic layer was washed twice with $1 \mathrm{M}$ $\mathrm{HCl}(100 \mathrm{~mL})$ and twice with $100 \mathrm{~mL}$ of brine, and then dried over $\mathrm{MgSO}_{4}$. The 
organic filtrate was reduced in volume to approximately $50 \mathrm{~mL}$ by rotary evaporation and then precipitated by pouring into $0{ }^{\circ} \mathrm{C}$ hexane. The precipitate was collected and dried under vacuum to yield dopamine acrylamide as an off-white solid (7.0 g, yield $32 \%$ ). ${ }^{1} \mathrm{H}$ NMR (400 MHz, DMSO- $\left.d_{6}, \delta\right): 2.54$ (t, $2 \mathrm{H}, \mathrm{CH}_{2}-\mathrm{CH}_{2}-\mathrm{NH}, J=8.0 \mathrm{~Hz}$ ), $3.25\left(\mathrm{dt}, 2 \mathrm{H}, \mathrm{CH}_{2}-\mathrm{CH}_{2}-\mathrm{NH}, J=6.0,8.0 \mathrm{~Hz}\right), 5.56(\mathrm{dd}, 1 \mathrm{H}, \mathrm{HCH}=$ trans to $\mathrm{CO}, J=$ 2.4, $10.0 \mathrm{~Hz}), 6.06(\mathrm{dd}, 1 \mathrm{H}, \mathrm{HCH}=$ cis to $\mathrm{CO}, J=2.4,17.2 \mathrm{~Hz}), 6.20(\mathrm{dd}, 1 \mathrm{H}, \mathrm{C} H=, J$ $=10.0,17.2 \mathrm{~Hz}), 6.43(\mathrm{dd}, 1 \mathrm{H}, \mathrm{Ar}, J=1.6,8.4 \mathrm{~Hz}), 6.57(\mathrm{~d}, 1 \mathrm{H}, \mathrm{Ar}, J=1.6 \mathrm{~Hz}), 6.62$ $(\mathrm{d}, 1 \mathrm{H}, \mathrm{Ar}, J=8.4 \mathrm{~Hz}), 8.15(\mathrm{t}, 1 \mathrm{H}, \mathrm{NH}, J=6.0 \mathrm{~Hz}), 8.69(\mathrm{~s}, 1 \mathrm{H}, \operatorname{ArOH}), 8.74(\mathrm{~s}, 1 \mathrm{H}$, $\mathrm{ArOH})$.
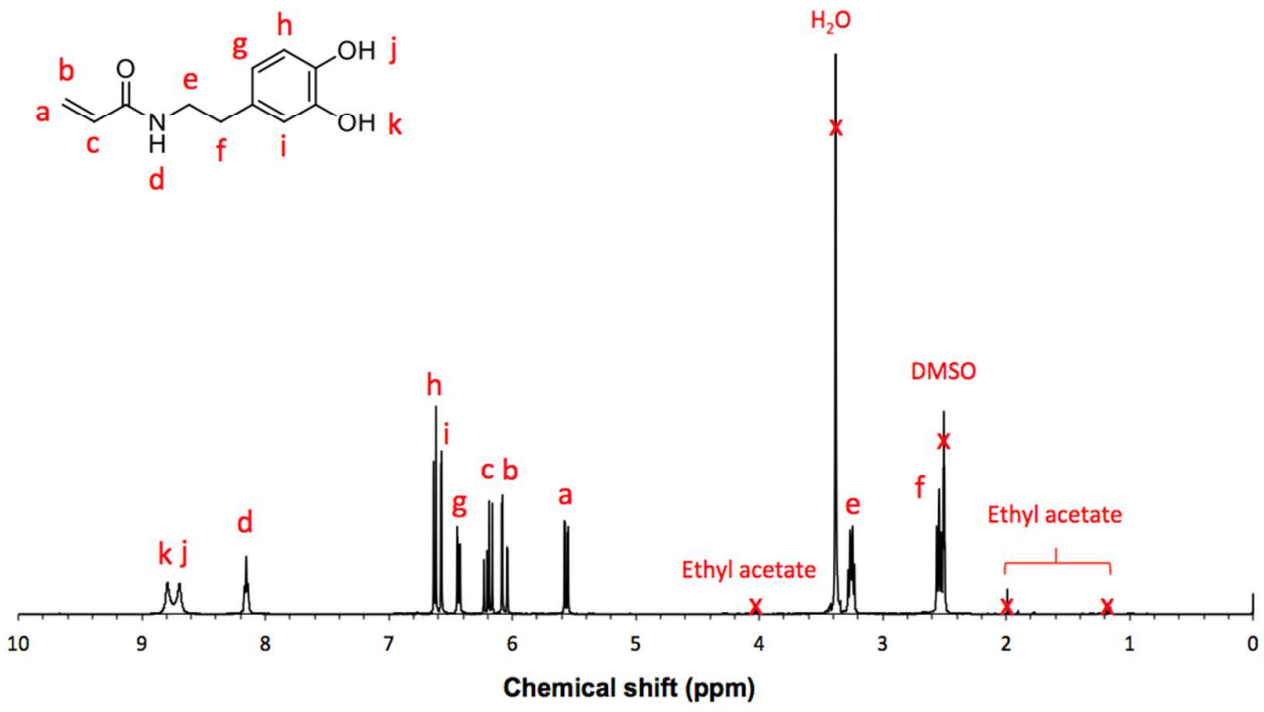

Figure S2. ${ }^{1} \mathrm{H}$ NMR spectrum of dopamine acrylamide (400 MHz, DMSO- $d_{6}$ ). 


\section{Synthesis of poly(dopamine acrylamide-co-butyl acrylate) (P(DA-co-BA))}

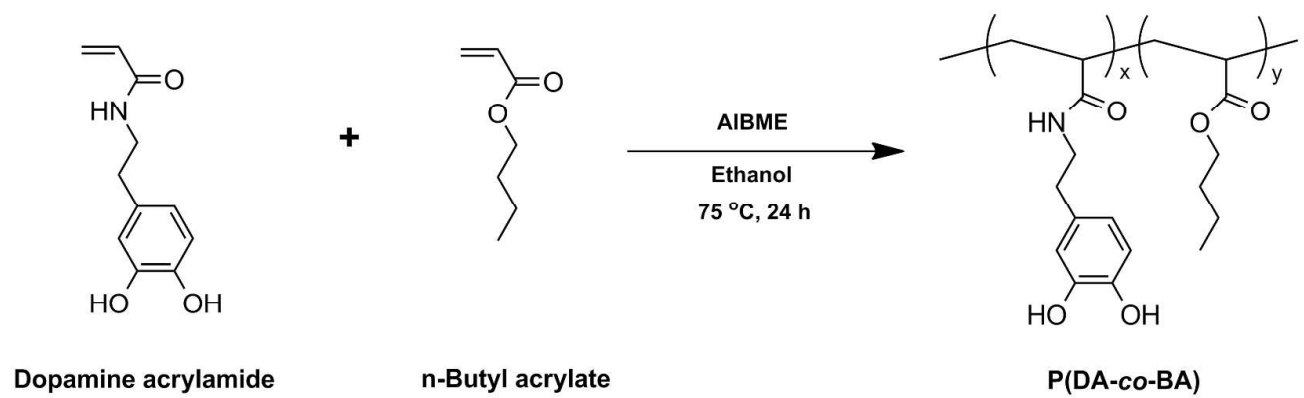

Scheme S3. Synthetic scheme of P(DA-co-BA).

This copolymerization is a modification of a previously reported procedure. ${ }^{4}$ To a nitrogen-purged $200 \mathrm{~mL}$ Schlenk flask, $8.0 \mathrm{~g}$ of DA (38.6 mmol), $222 \mathrm{mg}$ of dimethyl 2,2'-azobis(2-methylpropionate) (0.964 mmol), $22.0 \mathrm{~mL}$ of $n$-butyl acrylate (BA, 19.8 g, $154 \mathrm{mmol}$ ), and $96 \mathrm{~mL}$ of anhydrous ethanol was added. The solution was degassed via three freeze-pump-thaw cycles and backfilled with nitrogen. Then the solution was placed in an oil bath at $75^{\circ} \mathrm{C}$ and stirred for $24 \mathrm{~h}$. The solution was quenched by liquid nitrogen and reduced in volume to around $50 \mathrm{~mL}$ by rotary evaporation under reduced pressure. THF $(30 \mathrm{~mL})$ was then added, and the resulting solution was precipitated by pouring into $0{ }^{\circ} \mathrm{C}$ hexane. The precipitate was collected and dried under vacuum to yield a pale yellow solid (26.4 g, yield 95\%). ${ }^{1} \mathrm{H}$ NMR (400 MHz, DMSO- $\left.d_{6}, \delta\right):$ 2.17-0.88 (43H, aliphatic region), $2.47\left(2 \mathrm{H}, \mathrm{CONH}-\mathrm{CH}_{2}-\mathrm{CH}_{2}\right), 3.12$ (2H, CONH-CH2 $\left.-\mathrm{CH}_{2}\right), 3.97\left(8 \mathrm{H}, \mathrm{COO}-\mathrm{CH}_{2}-\mathrm{CH}_{2}-\mathrm{CH}_{2}-\mathrm{CH}_{3}\right), 6.62-6.40$ (3H, Ar), $7.86(1 \mathrm{H}, \mathrm{NH}), 8.71(2 \mathrm{H}, \mathrm{ArOH}) . \mathrm{GPC}(10 \mathrm{mM} \mathrm{LiCl}$ in DMF as eluent, polystyrene standards): $M_{\mathrm{n}}=78,000, M_{\mathrm{w}} / M_{\mathrm{n}}=2.1$. 


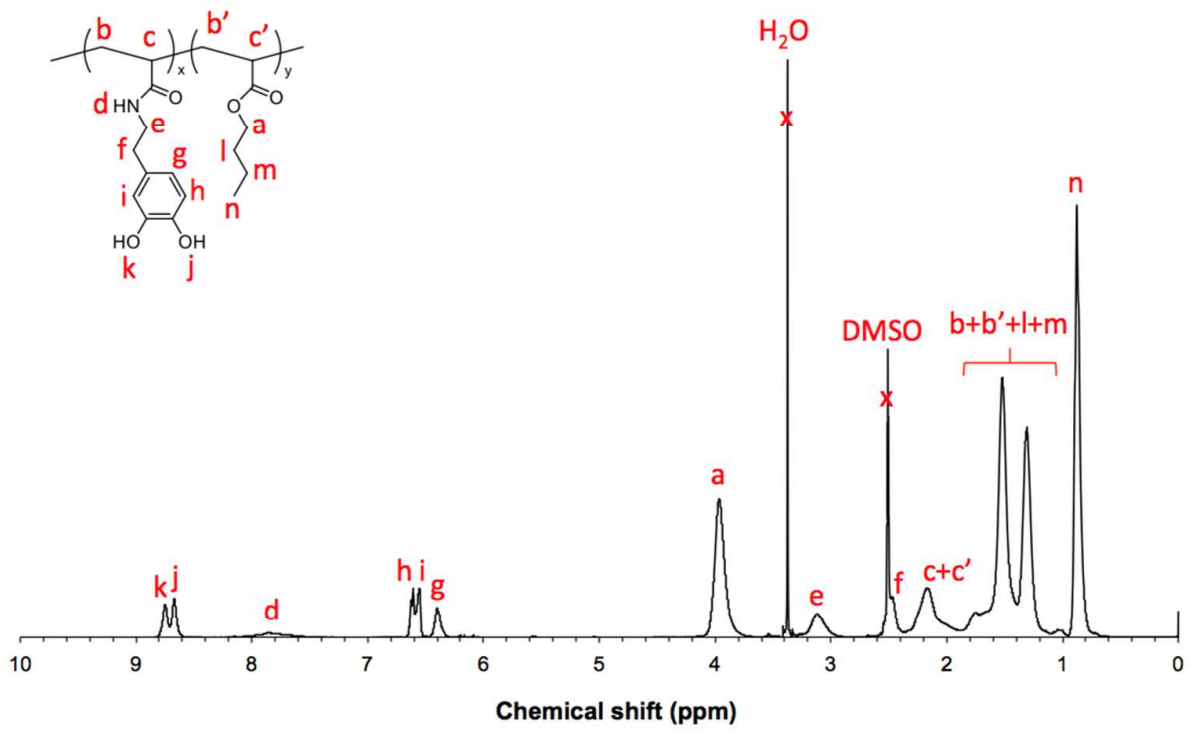

Figure S3. ${ }^{1} \mathrm{H}$ NMR spectrum of $\mathrm{P}(\mathrm{DA}-c o-\mathrm{BA})\left(400 \mathrm{MHz}\right.$, DMSO- $\left.d_{6}\right)$.

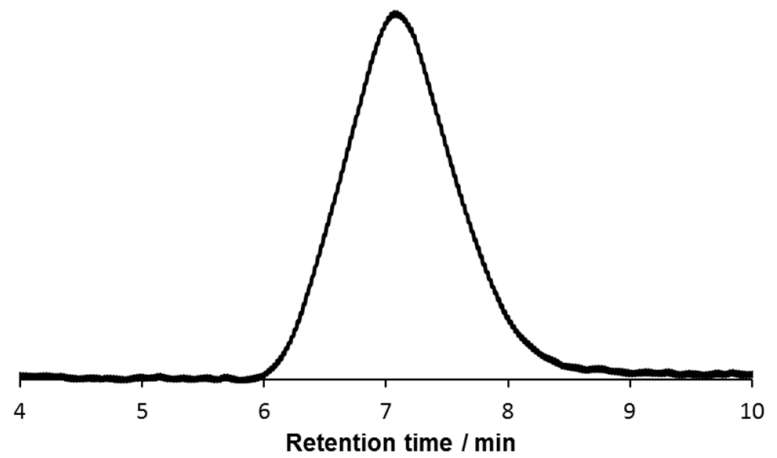

Figure S4. GPC trace of P(DA-co-BA). 


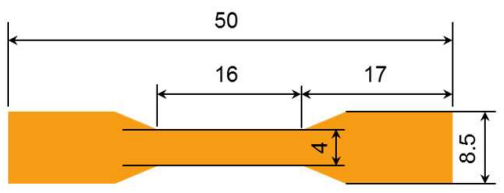

(mm)
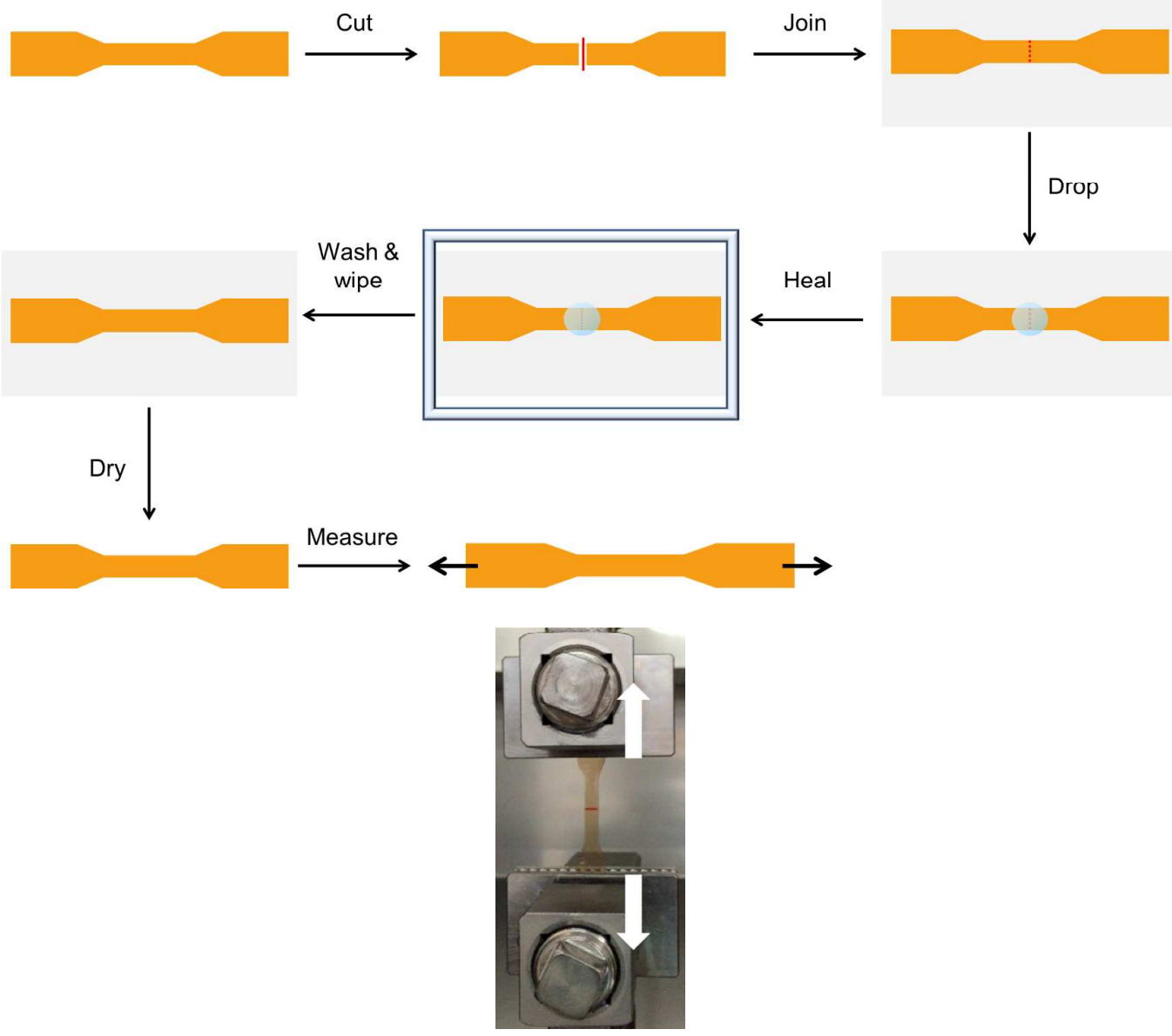

Figure S5. Dimensions of the dumbbell-shaped sample and schematic of the selfhealing procedure. 

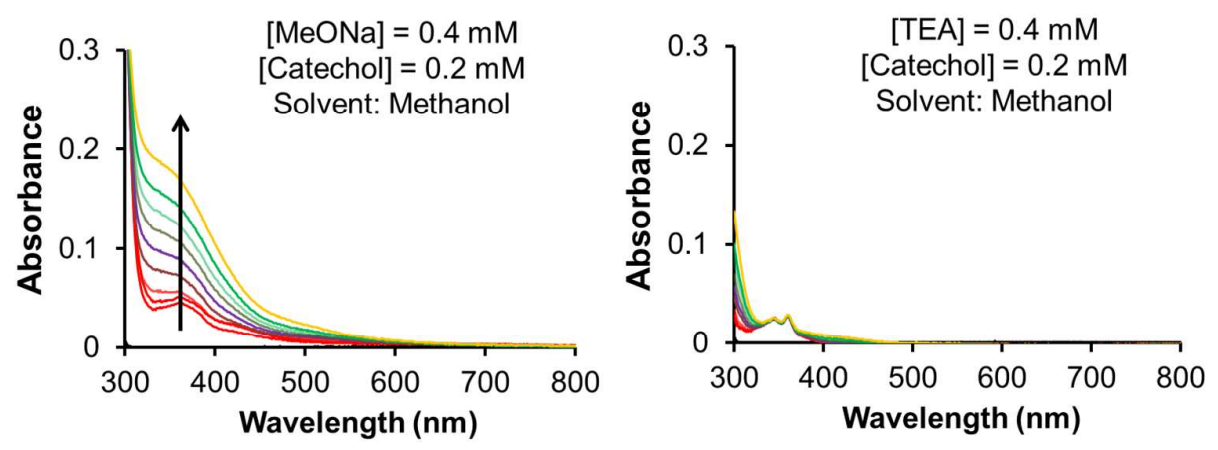

Figure S6. UV-vis absorption spectra of pyrocatechol solution in the presence of $\mathrm{MeONa}$ (left) and TEA (right) within $8 \mathrm{~h}$. 

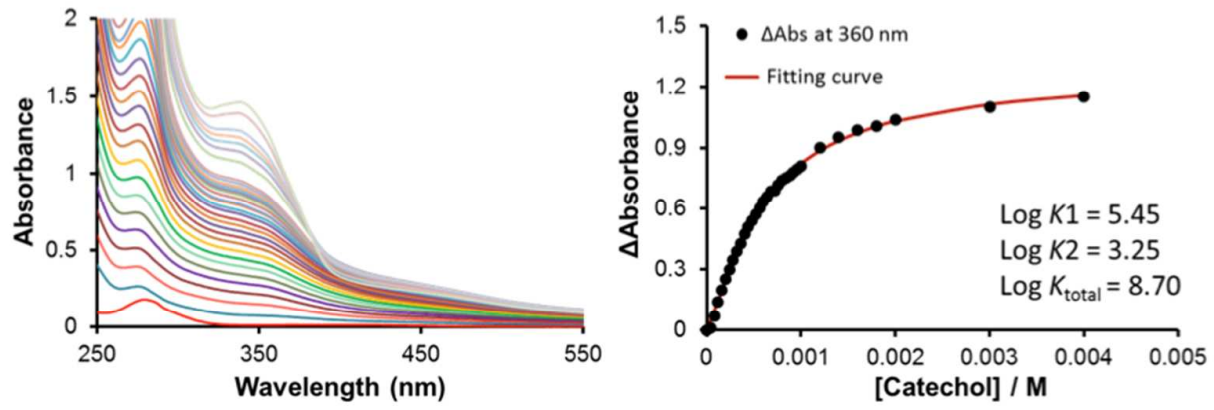

Figure S7. UV-vis absorption spectra of $\mathrm{Ca}^{2+}$-pyrocatechol complexes in methanol after $24 \mathrm{~h}$ (left) and a fitting curve (right). $\left[\mathrm{Ca}^{2+}\right]$ was fixed at $0.2 \mathrm{mM}$ and [pyrocatechol] was titrated. The absorbance at $360 \mathrm{~nm}$ originating from the $\mathrm{Ca}^{2+}$ pyrocatechol complexes was plotted against [pyrocatechol] and fitted using the program available at http://supramolecular.org/binding-constant-simulators/12-uv-visbinding-simulator based on a 1:2 binding model.
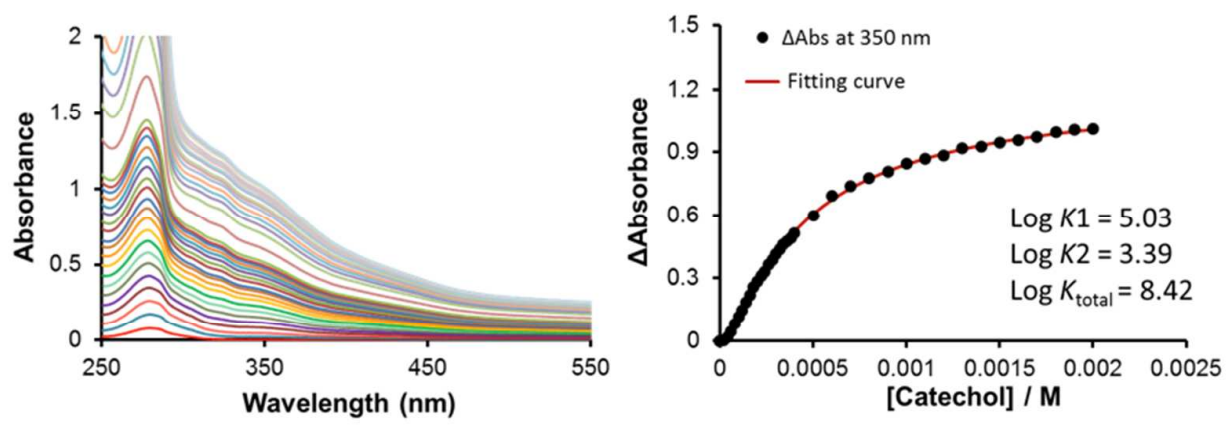

Figure S8. UV-vis absorption spectra of $\mathrm{Mg}^{2+}$-pyrocatechol complexes in methanol after $24 \mathrm{~h}$ (left) and a fitting curve (right). $\left[\mathrm{Mg}^{2+}\right]$ was fixed at $0.1 \mathrm{mM}$ and [pyrocatechol] was titrated. The absorbance at $350 \mathrm{~nm}$ originating from the $\mathrm{Mg}^{2+}-$ pyrocatechol complexes was plotted against [pyrocatechol] and fitted using the program available at http://supramolecular.org/binding-constant-simulators/12-uv-visbinding-simulator based on a 1:2 binding model. 


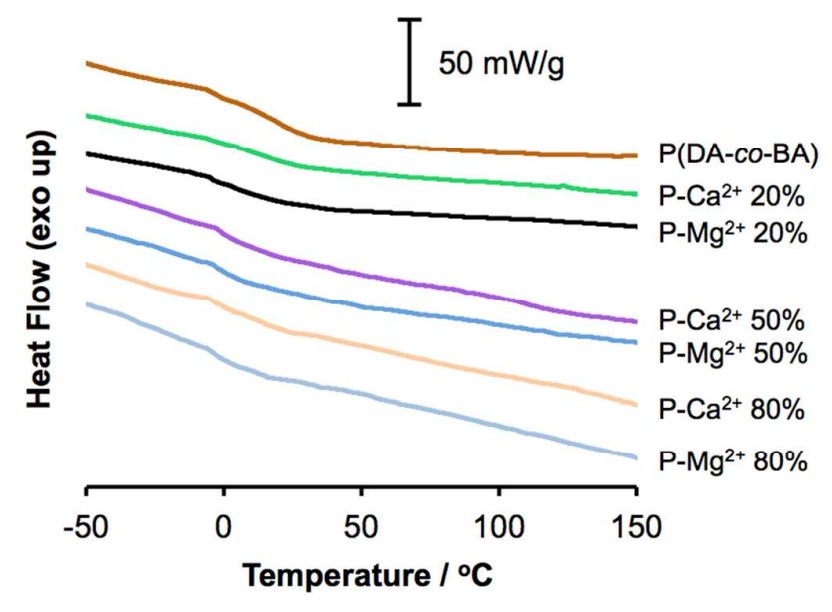

Figure S9. DSC traces of $\mathrm{P}(\mathrm{DA}-\mathrm{co}-\mathrm{BA})$ and metallopolymers.
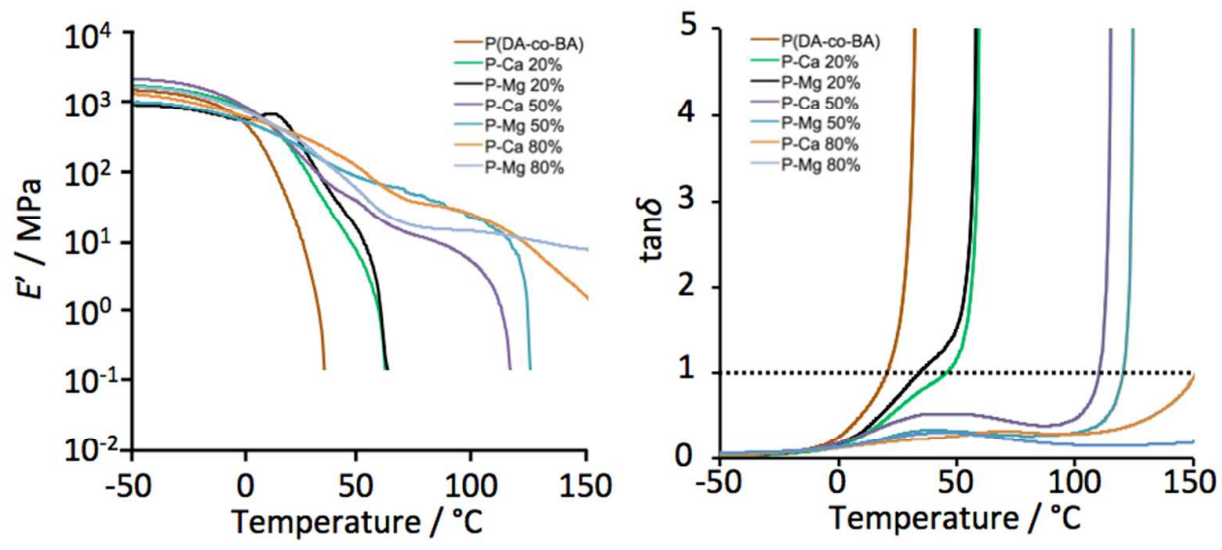

Figure S10. Storage modulus (E') and tan $\delta$ curves of $\mathrm{P}(\mathrm{DA}-c o-\mathrm{BA})$ and metallopolymers. 


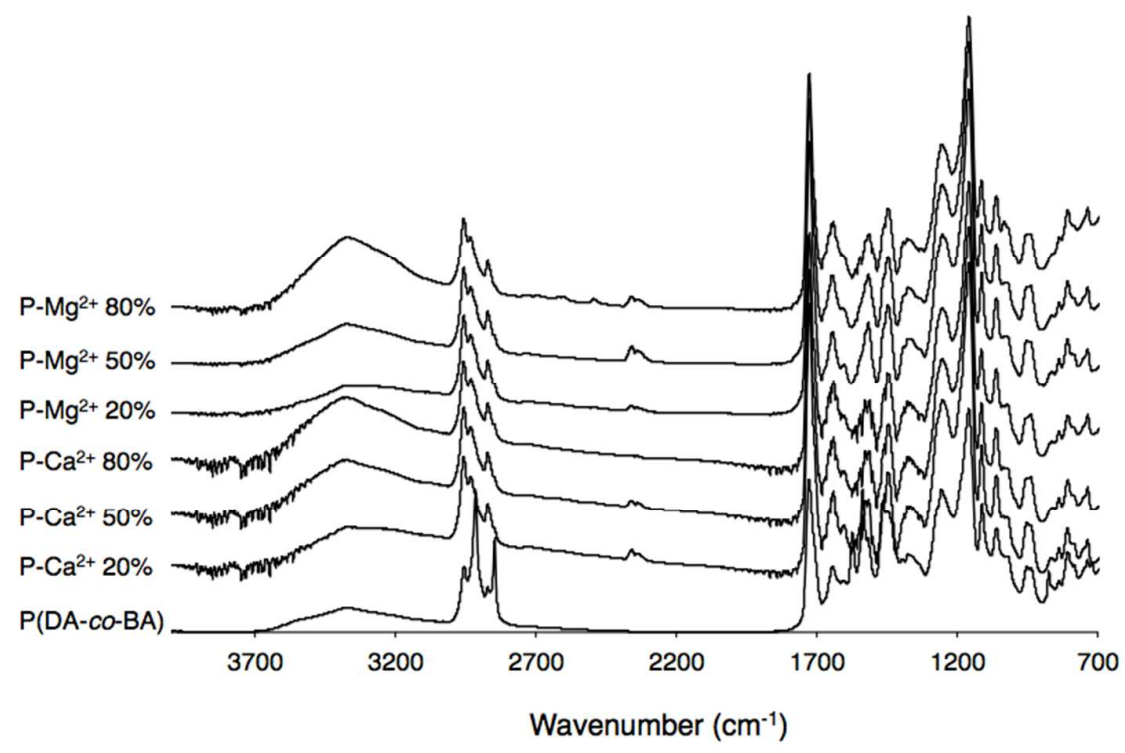

Figure S11. ATR-FTIR spectra of P(DA-co-BA) and metallopolymers.

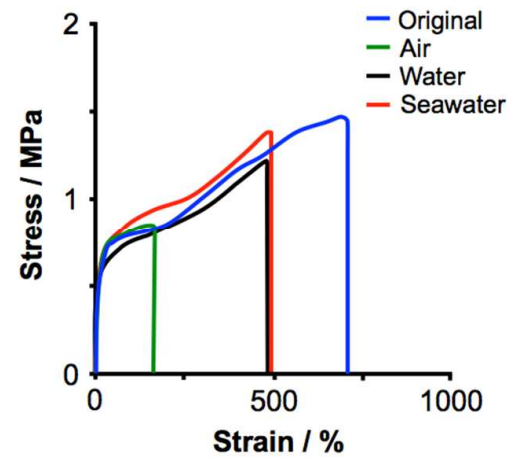

Figure S12. Tensile test results of $\mathrm{P}-\mathrm{Na}^{+} 20 \%$ : original samples and samples healed in air, water, and seawater for $24 \mathrm{~h}$. 
Table S1. Salt content of artificial seawater

\begin{tabular}{ccc}
\hline Constituent & $\begin{array}{c}\text { Weight in } 100 \mathrm{~mL} \text { of deionized water } \\
/ \mathrm{g}\end{array}$ & $\begin{array}{c}\text { Metal concentration } \\
/ \mathrm{mM}\end{array}$ \\
\hline $\mathrm{NaCl}$ & 2.4 & 0.439 \\
$\mathrm{Na}_{2} \mathrm{SO}_{4}$ & 0.5 & \\
$\mathrm{MgCl}_{2}$ & 0.4 & 0.053 \\
$\mathrm{CaCl}_{2}$ & 0.1 & 0.009 \\
\hline
\end{tabular}

Table S2. Summary of $\mathrm{P}-\mathrm{Na}^{+} 20 \%$ toughness and self-healing efficiency in air, water, and seawater.

\begin{tabular}{cccccccc}
\hline & Original & \multicolumn{2}{c}{ Air } & \multicolumn{2}{c}{ Water } & \multicolumn{2}{c}{ Seawater } \\
\cline { 2 - 7 } Sample & $\begin{array}{c}\text { Toughness } \\
/ \mathrm{MPa}\end{array}$ & $\begin{array}{c}\text { Toughness } \\
/ \mathrm{MPa}\end{array}$ & $\begin{array}{c}\text { Self-healing } \\
\text { efficiency } \\
/ \%\end{array}$ & $\begin{array}{c}\text { Toughness } \\
/ \mathrm{MPa}\end{array}$ & $\begin{array}{c}\text { Self-healing } \\
\text { efficiency } \\
/ \%\end{array}$ & $\begin{array}{c}\text { Toughness } \\
/ \mathrm{MPa}\end{array}$ & $\begin{array}{c}\text { Self-healing } \\
\text { efficiency } \\
/ \%\end{array}$ \\
\hline $\mathrm{P}-\mathrm{Na}^{+} 20 \%$ & $9.0 \pm 2.1$ & $0.7 \pm 0.7$ & $7.8 \pm 7.8$ & $3.9 \pm 1.1$ & $43 \pm 12$ & $3.3 \pm 0.5$ & $37 \pm 6$ \\
\hline
\end{tabular}




\section{References}

(1) Hammaker, J. R.; Mash, E. A., Synthesis and Characterization of a Poly(acrylamide) with Pendant 1,4-piperazine-2,5-dione Moieties via Postpolymerization Cyclization. J. Macromol. Sci., Part A: Pure Appl. Chem. 2008, $45,865-871$.

(2) Pugh, C.; Raveendra, B.; Singh, A.; Samuel, R.; Garcia, G., Design and Regioselective Synthesis of (2-Bromo-2-alkoxycarbonyl)ethyl

Acrylates as Inimers for Hyperbranched (Co)Polyacrylates Synlett 2010, 13, 1947-1950.

(3) Sparks, B. J.; Hoff, E. F. T.; Hayes, L. P.; Patton, D. L., Mussel-Inspired ThiolEne Polymer Networks: Influencing Network Properties and Adhesion with Catechol Functionality. Chem. Mater. 2012, 24, 3633-3642.

(4) Lee, H.; Lee, B. P.; Messersmith, P. B., A Reversible Wet/Dry Adhesive Inspired by Mussels and Geckos. Nature 2007, 448, 338-341. 